\title{
Reflecting, adapting and learning in small software organizations: an action research approach
}

\author{
Suzana Cândido de Barros Sampaio, Marcelo L. M. Marinho, Alexandre J. H. de O. Luna, Hermano P. de Moura ${ }^{1}$ \\ ${ }^{1}$ Informatics Center - Cin, Federal University of Pernambuco \\ Recife, PE, Brazil \\ \{scbs2, mlmm, ajhol, hermano\}@cin.ufpe.br
}

\begin{abstract}
Software Engineering activities are context based and carried out by people, within its culture and project actuality. Consequently, it demands a great deal of social relations. In order to better understanding these challenges faced by software development projects, we have had to go beyond the actual mindset, literature and bodies of knowledge. This paper is a result of an empirical research, aligned with evidence-based Software Engineering, about studies conducted on five software development Micro and Small Enterprises in Brazil, during 22 months, between July-2012 and May-2014. We have adopted a participant observer ethnographic study, resulting in intervention based on action research. The interventions happened several times, leading into continuous and constructive process of reflecting and learning. As a result, we have observed the emergence of a practical problem solving culture, from a collaborative immediate situation, which expanding the actor's competencies in every cycle of its execution. Although every organization had its own major problem to be dealt with, our findings point out to some common problems and emerging action strategies to handle with these challenges.
\end{abstract}

Keywords - action research, qualitative research, project management, project actuality.

\section{INTRODUCTION}

Over the past 20 years, there has been a substantial improvement in the quality and rigor of research in PM [1]. Project has become more relevant to organizational change and growth as it is used to achieve business objectives. According to Shenhar Dvir, Levy and Maltz, projects are a unique way for organizational change, innovation and face the competitive market's reality [2]. Mintzberg [3] advocate that Project Management (PM) is important to anyone who is effected by its practice that means the entire organizational world. In order to take full advantage from PM practice, organizations, teams and practitioners must adopt new ways of learning, thinking and reasoning in action.

Nowadays, research empirical method has become part of the Software Engineering research practice. In the experimental software engineering paradigm, the relationship between practitioners and researchers is highly symbiotic, where researchers need laboratories to observe and manipulate variables in vivo, and project context seems as an ideal environment to do that. In the other hand, practitioners feel the need to understand how best they can build and maintain their organizational system, and researchers can help them to achieve this end [4]. In order to be more competitive, PM practitioner must also understand how to step up and improve its competencies, processes, overcoming their problems and achieving better results. Indeed, action research has emerged as a good strategy to accomplish that goal.

In addition, Micro and Small Enterprises (MSEs) have a great importance in any country's socioeconomic scenario, and in Brazil it is no different. A research conducted by the Brazilian Institute of Geography and Statistics (IBGE) in 2010 depicted that this kind of organization represents more than 99\% (5.7 million) of Brazilian companies and they represent $60 \%$ of the jobs across the country. However, it represents no more than $20 \%$ (US 700 billion) of the Brazilian GDP ${ }^{1}$ [5]. In fact, it is an expressionless percentage when compared to other nations, showing that there is still much opportunity for growth to this economic sector. Among ICT companies over $85 \%$ can be classified as Micro or Small Business [6].

From this perspective, and aiming at addressing this growth opportunity, as well as the expected benefits of organization and PM practices enhancement, we have conducted five action research studies in small software development organization in the northeast of Brazil. It is important to point out that the organizations in these studies did not know their real problems, that is way ethnographic techniques [7] were necessary in order to diagnosis the major challenges. Each organization, team or project had its own problems to solve. This is a part of a broader research [8] on project actuality were exploratory and systematic literature review [9] and ethnographic studies were conducted before the action research. By facing project as our research field and by involving the practitioners, with the real and major problems identified, researchers and practitioners can embrace the reflective practitioner in its actuality, willing to rethink, undo, redo and learn.

This paper is organized as follows. Next section gives an overview of the action research method, its main concepts, steps and principles. Section 3 exhibit a brief sample's summary, and five organizational contexts. Section 4 presents the research design and steps executed before the study. Section 5 describes the approach used. In addition, Section 6 presents some actions and feedback obtained as studies result.

\footnotetext{
${ }^{1}$ Gross Domestic Product.
} 
Finally, in Section 7 final considerations and limitations are discussed.

\section{ACTION RESEARCH}

Scientific methodology is necessary to make the research results more reliable and reproducible by other researchers. According to Zelkowitz [10], the social challenges dealt with by researchers in Software Engineering investigations makes Action Research (AR) a useful research methodology due to its characteristics and possibility of obtaining relevant results.

While most empirical research methods attempt to observe the world, as it currently exists, action researchers aim to intervene in the studied situations for the explicit purpose of improving the situation [11]. The knowledge gathered from research empowers particular individuals or groups, and facilitate a wider change. The AR's application focus involves solving organizational problems through interventions, while at the same time contributes to teams and organizational knowledge. In our studies, we had the purpose of improving the organizations and its teams, by overcoming their problems and helping team members to engage in reflection.

Davison, Martinsons and Kock [12], suggests a unidirectional flow for AR, with diagnosis followed by planning, intervention, evaluation and reflection. In order to better suit to small enterprise and for teams' reflection, rethinking and learning, the major steps were adapted. In addition, to avoid just focusing on the iceberg top or in a specific effect (but not in its causes), we carried out the AR after ethnographic based study. Using ethnography as a technique to proceed the diagnosis stage from action research.

\section{THE IN-VIVO SAMPLE}

The research sample is comprised by MSE in the northeast of Brazil. Four of them were from Recife (A, B, C and D), and two of them were from a small city over $700 \mathrm{~km}$ away ( $\mathrm{F}$ and $\mathrm{G})$. Our research is context and time dependent, and was conducted along from July, 2012 to May, 2014. Organization A has nearly 10 years of experience in the IT industry, founded in 2004 to provide solutions in managing industries, services and trade. They have a product developed in Delphi with firebird and one in Java JSP for another purpose. A team of five developers took care of over ten clients. The owner was centralizing and the ambient was noise and the Delphi team was demotivated and tired. The room and machines were new, clean and organized. The most expected problem to be solved was to overcome not being able to estimate correctly and precisely.

Organization B was the oldest and biggest one in the sample with 25 years in the market, and two teams. The organization had two solid products, with the biggest clients, also partnership with other organizations that combined presented an even more solid and wider solution. If a client wants something different but still related to their products, they would get the challenge to gain market. Both observed teams worked in two distinct Delphi product. The biggest challenge for their teams was to stop clients and manager interference that generated lack of commitment and motivation. In addition, the major challenge for the organization was to overcome lack of visibility and trust on teams work. The organization had level G of MPS-SW [13] and already had their work organized as projects.

Organization D was the most mature one, used to have MPS-SW [13] level G, but it expired. With 13 years in the market, it had a nice renewed office. The owner was from IT world, but along our research, we never saw him with the team. It was a family business, although the manager was not part of the family. The study initiated with one manager and changed along the way. The change was freighting, but team got more cohesive, less bureaucratic and productive after this change and along our study. Besides de developers, one tester, quality assurance that could also develop made the team. A part time trainee tester was also involved along the project.

Organization $\mathbf{F}$ was the hardest one to commit to the research. They had the nosiest room, the worst scenario and took longer to build trust and finally engage in action. The owner was really busy selling, but he originally messed everyone's plans. He gave a percentage in the society for his two best men, both with over 15 years working with him. With 2 hours lunchtime, $100 \%$ of the organization went home to eat and rest. The either walked home or used motorcycle to get around. Many times the first researcher waited outside in over $35^{\circ}$ degree Celsius, feeling $45^{\circ}$ sun.

Out of them all, Organization G had the most technical $\mathrm{PM}$, one of the two owners. One owner dealt with sales, and took care of the support team. The other, great researcher in action and enthusiast of our research. He manage to learn quick, try hard to rethink, reflect and move forward. He counted as one developer, although his help was sporadically. One developer was 30 hours only, but one of the best programmer of the team. With two hours lunch, everyone went home. A young nice and committed team.

\section{PReVious to The ACtion}

\section{A. Planning the studies}

The organizations were chosen by convenience, all of them were indicated by SoftexRecife ${ }^{2}$. It supports micro small software development organizations through training, process improvement, testing and other services.

The authorization was written as an invitation letterconsent form signed by the organization high management, or site coordinator and the first researcher. The letter states researchers' names and affiliation, the research goal, procedures and techniques and confidentiality rules. The end criteria was a bit abstract, but the idea was to keep on researching until the main problems are overcame, challenges are dealt with and both parties involved are satisfied. In addition, a research plan was presented to the team to guarantee their understanding and commitment.

\footnotetext{
2 The Software Technology Excellence Center in Recife, a civil non-profit association, established on Nov.8th, 1994 with a mission to increase the competitiveness of ICT companies (http://www.recife.softex.br/).
} 


\section{B. Diagnosis - The Ethnografic Study}

Schensul [14] presents ethnography as a scientific approach to discovering and investigating social and cultural patterns and meaning in communities, institutions, and other social settings. Ethnographic studies in software engineering are valuable for discovering what really goes on in particular technical communities, and for revealing subtle but important aspects of work practices [11]. We saw as way of unveiling the major problems, faced by the team or project manager independent of the source. All problems were grouped in a backlog, prioritized by the manager, and always revised along the intervention. Every finding came from several evidences and a causality analysis made in the ethnographic study.

Table I depicts the most common problems in between the five organizations. The problem backlog was presented in questions in order to confirm it and prioritize them. Moreover, the idea was also empower the reflexive practitioner and the practitioner-researcher. To each organization was also pointed the evidences that pointed or corroborated each problem.

TABLE I. MOST COMMIN PROBLEMS

\begin{tabular}{|c|c|c|}
\hline \multirow{2}{*}{ Org. } & \multicolumn{2}{|r|}{ Problem Backlog } \\
\hline & Problem & Reflecting question \\
\hline $\begin{array}{l}\text { A, B, F } \\
\text { and } G\end{array}$ & $\begin{array}{l}\text { (I) Absence of } \\
\text { Reflection }\end{array}$ & $\begin{array}{l}\text { Does your team have any time to reflect } \\
\text { about what went wrong and what could } \\
\text { have been done better? }\end{array}$ \\
\hline $\begin{array}{l}\text { A, B } \\
\text { and } F\end{array}$ & $\begin{array}{l}\text { (II) Blaming } \\
\text { Culture }\end{array}$ & $\begin{array}{l}\text { Is the blaming mood around? Is your team } \\
\text { more worried about blaming someone for } \\
\text { the bug, problem or issue than to solve it? }\end{array}$ \\
\hline $\begin{array}{l}\text { A, B, } \\
\text { D, F } \\
\text { and } G\end{array}$ & $\begin{array}{l}\text { (III) Blind } \\
\text { Capacity }\end{array}$ & $\begin{array}{l}\text { Do you know what your team is capable } \\
\text { of? How much work can you do, how } \\
\text { much requirements can we compromise in } \\
\text { a week, a cycle, a month? }\end{array}$ \\
\hline $\begin{array}{l}\text { A, B, } \\
\text { D, F } \\
\text { and } G\end{array}$ & $\begin{array}{l}\text { (IV) Living } \\
\text { the Problems }\end{array}$ & $\begin{array}{l}\text { Are living the problems instead of solving } \\
\text { the problems? }\end{array}$ \\
\hline $\begin{array}{l}\text { A, B } \\
\text { and } F\end{array}$ & $\begin{array}{l}\text { (V) } \\
\text { Unproductive } \\
\text { environment }\end{array}$ & $\begin{array}{l}\text { Is your team ambient too noisy or the } \\
\text { interruptions are driving away your } \\
\text { productivity? What are nowadays our } \\
\text { team's productivity villains? }\end{array}$ \\
\hline $\begin{array}{l}\text { A, B, } \\
F \text { and } \\
G\end{array}$ & $\begin{array}{l}\text { (VI) Unclear } \\
\text { Goals }\end{array}$ & $\begin{array}{l}\text { Do you have an unclear goal? Can't your } \\
\text { team know or tell what must be done? }\end{array}$ \\
\hline $\begin{array}{l}\mathrm{A}, \mathrm{B}, \mathrm{F} \\
\text { and } \mathrm{G}\end{array}$ & $\begin{array}{l}\text { (VII) Lack of } \\
\text { Quality }\end{array}$ & $\begin{array}{l}\text { Is your product producing more bugs then } \\
\text { you can correct? Is your backlog of bugs } \\
\text { bigger then you requirements backlog? }\end{array}$ \\
\hline $\begin{array}{l}\text { A, B, F } \\
\text { and } G\end{array}$ & $\begin{array}{l}\text { (VIII) Lack of } \\
\text { Visibility }\end{array}$ & $\begin{array}{l}\text { Are you unaware of what is going on with } \\
\text { your team's activity? }\end{array}$ \\
\hline $\begin{array}{l}\text { A, F } \\
\text { and } G\end{array}$ & $\begin{array}{l}\text { (IX) Endless } \\
\text { Operation }\end{array}$ & $\begin{array}{l}\text { Is your work with no end neither } \\
\text { beginning and seams to take forever with } \\
\text { no partials winnings? }\end{array}$ \\
\hline $\begin{array}{l}\text { A, B, F } \\
\text { and } \mathrm{G}\end{array}$ & $\begin{array}{l}\text { (X) Lack of } \\
\text { Commitment } \\
\text { and trust }\end{array}$ & $\begin{array}{l}\text { Are all your initiatives top down? Is the } \\
\text { owner or team leader the only one doing } \\
\text { the talk? Is the goal always unrealistic? } \\
\text { Do you care to make sure that your team } \\
\text { buys what you say? }\end{array}$ \\
\hline $\begin{array}{l}\text { A, B } \\
\text { and } F\end{array}$ & $\begin{array}{l}\text { (XI) Lack of } \\
\text { Motivation }\end{array}$ & $\begin{array}{l}\text { Does your team never catch a break? Do } \\
\text { you remember that they are people? Does } \\
\text { your team's fear slow them down? Cannot } \\
\text { see what can you do next? }\end{array}$ \\
\hline
\end{tabular}

\section{THE APPROACH}

This section presents the approach that encompasses the action research, team reflection and learning. Beginning with the adaptation from the Cyclical AR Process Model [12] followed by the reflection process.

\section{A. Cyclical Research Action Process Model Adaptation}

The Diagnosis was substituted by the research setup and the ethnographic study, as explained last section. In this stage the research field was defined, an agreement is settled and the problems are analyzed by the ethnographic study, similar to what Davison, Martinsons and Kock [12] proposal. The Action Planning stage uses the same idea as the one presented by the authors, where actions are defined for the diagnosed problems, although we included a reprioritization in each cycle, accommodating new prioritized-disturbing problems.

Intervention corresponds to the planned actions implementation exactly as idealized by the author [12]. The biggest adaptation is surrounding the Reflection activity; it does not only support the information flow between participants and the organization as presented by Davison, Martinsons and Kock [12]. As we deal with small organization, most organization's member were involved as researchers in action and just organization B needed to make the information flow, all the others had all team members engaged and involved. In our studies, reflections occurred before Action Planning, as presented in Fig. 1.

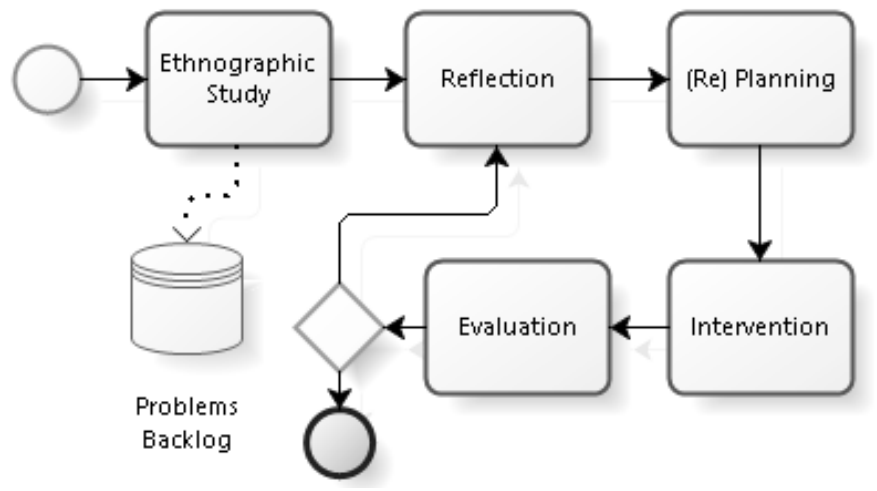

Fig. 1. Action Research Strategy. Source: Own elaboration.

After the intervention, the Evaluation took place, following the authors' idea of using theoretical support to analyze actions' effects and results. It was followed by another cycle started by reflection and learning activity.

\section{B. Reflection Activity}

The reflection sections represented a learning trigger to each context or problem discussed. It allowed the team to familiarize with some theory and question their status quo, in order to better see the problem and engage in overcoming it. The reflection activity was carried with the help of a macro activity and has the following goals: (i) conduct active interview or participant observation [15], [16]; (ii) get those who are being researched to play an active role in the process; rather the being passive subjects [16]; and help team to engage 
in reflection about the best way to overcome a problem, a conflict or an improvement opportunity.

Every time an opportunity is identified, is a good time to reflect, although we used the reflection to start the cycle, to analyze the problems, situations and to rethink some ideas, approaches and strategies, resulting in the action plan. The steps necessary to accomplish this activity were:

- Identify conflicts, problems and singularities;

- Consider project actors researchers in action who must continuously question their actions and intentions in light of real-world situations [17];

- Evolve the reflection around questions [16], such as How, When and Why;

- Talk about the identified problem, conflict, singularities. Ask how can they overcome such problem, or how could it be done in a different way;

- Stimulate reflection; invite them to challenge the status quo, to analyze different ways of reasoning. And;

- Document findings. Always take notes, the quote spoken, the actor involved, the situation it came out and context it occurred.

As these activities' result, we have identified actions from project reflection, and an action plan was created.

\section{ACTIONS}

Plenty where the actions we carried along the study. Some of them target not just the problems but foundation for future actions. For example, problem I, Absence of Reflection, without overcoming this barrier, probably once the study finished they would stop the reflection and rethinking. For that, one of the first actions was to introduce a Retrospective Meeting to all the organizations in the sample, except for $D$ that already used it. Each organization organized itself differently as presented in Table II.

TABLE II. REFLECTION MOMENT.

\begin{tabular}{|c|l|}
\hline Org. & \multicolumn{1}{|c|}{ Reflection Moment chosen by each Organization } \\
\hline A & $\begin{array}{l}\text { Meeting after each important deliverable - end of } \\
\text { implementation cycle. }\end{array}$ \\
\hline B & $\begin{array}{l}\text { Retrospective meeting after the sprint - two or three weeks } \\
\text { sprint. }\end{array}$ \\
\hline D & Meeting after two sprints of a weeklong. \\
\hline F & Meeting every milestone, monthly. \\
\hline G & Retrospective meeting in the end of every other sprint. \\
\hline
\end{tabular}

Another problem that we have faced was the Endless Operation (IX). Only Organizations B and D were already organized as projects. The problems effects were many. One of the evidences for Organization $\mathbf{G}$ was an affirmation in a meeting saying, "Today there are about four versions per month or more. It is costly and takes too much time." Every organization reflected about their own project definition, such as: new product version; a product gap to be accomplish in order to meet customer needs; a slice of time, two to four weeks of work, with demands from several clients or several systems; a new system module delivery to meet legal demand; among others more traditional. Even though Organization B was already organized as projects, the reflection regarding the project concept was necessary due another problem, blind capacity, the difficulty on coordinating outside project with inside projects. The reflection included the higher management, the operational director and some other leaders that were senior employees. They were only organized timely (every 6 weeks a new official deploy), and the objective was to synchronize with outside projects and the main strategic goals. For that every two weeks they had their own "portfolio" meeting and they initiated to prioritize demands that would turn into projects. A few "outside small projects" (gaps to implant a product in a new client, legal demands, new demands from a strategic client) could turn into one project. In addition, a medium "outside project" (new product) could turn into a few projects. For the higher management this was the best result from our research.

In response to problem VII, all organizations in the sample reflected about the quality of their products and the return rate (associated with number of requirements with bugs). Different actions were conducted, although almost every team manage to initiate or enhance their testing tasks and skills. Rethinking the activities already done about the product's quality, some organizations figure it out that they had no "done" concept for their tasks and no success definition for their cycle or project. Organization B found problems such as: "Deployment on the client currently generates inconvenience to the elaborated Project Plan. Several development and testing activities are carried out in the field and sent to the team impacting business goal and the quality of the issued release"; and "team member's activity were submitted on branch of the Project, authorized by the PO, impacting activities and quality of the product and project". Some actions tried to address this misuse of the process and practice.

In resume, the organizations engage on several cycles of rethinking in order to "Enhance the product's quality", with the following derivate actions related to test: new test activities (A, F, G); work with product risk analysis (A, F); using support analyst for testing (A, F, G); hiring or allocating new test force (B, D); acquiring New tools - Testlink ${ }^{3}(D)$.

Problem $V$, related to lack of productivity, had the most unexpected and different actions. One of them was called "Major changes in order to achieve productivity or cohesion teams". As an example, Organization B had a re-distribution of the teams inside their room to sit together, reduce the noise and facilitate the communication. Organization $\boldsymbol{G}$ had a total change in the organization's physical structure. Coming from a single room with a hybrid profile (developer + support analyst) to everyone, but the owner, to separate rooms and separate positions. After four years, the development team got its own room and had only developing activities with three people only, plus two open spaces. The senior developer, that is also a small partner, took over the team management. One

\footnotetext{
3 http://testlink.org/
} 
developer stayed in the support room, the only one really divided in between teams (support and developer), but he came to the room as demanded. The support team's room was divided with the owner, by a full brick-wall and some glass. A huge task board was organized. In addition, 10 minutes break every four hours to do whatever they want; better use of inside phones and less yelling around, as well as a mobile phone politics for a better-focused and productive group. In general, the action was the definition of a good coexistence policy or productivity policies, towards a productive team.

Many actions were executed facing the problems exhibit in Table I. Always coming from a situation or problem and aiming on overcoming it, such as: going from not knowing what we are capable of and how much time is necessary to accomplish some task, to estimative using complexity and relative sizing; from living the problems to solving the problems; from lack of behavior competence to better leadership skills; from lack of visibility to a transparent management system; and so on. Theories were used to present during reflections section as possible strategies and techniques.

Each organization took at least three formal cycles (D and F) to six cycles (B). In each cycle, different problems were faced and dealt with. Feedback from the AR, was qualitative. We recorded the feelings of progress and evolution in all problems reflected and treated. The most interesting ones were:

- $\quad \mathbf{B}$ - "The Portfolio vision was the best action of all. We can finally be predictable and we can finally give some pre-visibility to our clients".

- $\quad$ - "We had tried that once by ourselves and did not work. We got more agile and threw away heavy-casted process. You were our fairy godmothers".

- $\mathbf{G}$ - "Every time you came here we learned something new or we gain some new perspective. We are more organized and predictable now; we will try to keep the reflection at least every other month".

\section{CONCLUSION AND FUTURE RESEARCH STUDIES}

The idea of this study from the beginning was to help small software development organizations to achieve better results, stay competitive, enhance teams' competences and do not let projects be predestined to fail or to lack of its potential. In order to go beyond the "out of the shelf solutions", action research helps to empowered reflexive practitioners to rethink the status quo and overcome their problems. We encourage a management thinking that inspires different ways of reasoning, reflecting and learning.

This paper presented the action research approach used as a reflecting, adapting and learning tool in small software development organizations in the northeast of Brazil. This step was primordial to a larger research within the experimental Software Engineering; aiming on understanding project actuality, and how to support small organizations to engage in reflection and learning even after the researchers have left the research field. Our findings denote that Software Engineering is all about reflecting and learning as a team.

This study empowered a few organizations and teams to work as reflexive practitioners. Great changes happened after a few cycles of action research. Although this research is context dependent, we sure believe that still leaves a great opportunity for further work to improve small and medium software development organizations, this large potential market in Brazil.

\section{ACKNOWLEDGMENT}

This study would not have been possible without all the support and believe from the five organizations that opened their doors to us and engage themselves as researchers in action, willing to listen to us and reflect. The authors also would like to thank CAPES for supporting this research. And to SoftexRecife for introducing us to the organizations in the sample.

\section{REFERENCES}

[1] J. R. Turner (2010). Evolution of project management research as evidenced by papers published in the International Journal of Project Management, 28: 1-6.

[2] A. J. Shenhar, D. Dvir, O. Levy and A. C. Maltz (2001). Project success: a multidimensional strategic concept. Long range planning, 34(6): 699725.

[3] H. Mintzberg (2009). Managing. Berrett-Koehler Publishers.

[4] V. Basili, R. Selby and D. Hutchens (1986). Experimentation in software engineering. IEEE Transactions on, (7), 733-743.

[5] IBGE (2010). Reserach on Comunication and Information Techonologies in organizations, 2010. ftp://ftp.ibge.gov.br/Tecnologias_de_Informacao_e_Comunicacao nas_Empresas/2010/comentarios.pdf accessed in Ago 8th 2014.

[6] ABES, 2013. Brazilian Software Market: scenario and trends. 1Ed. São Paulo: ABES.

[7] M. Hammersley and P. Atkinson (2007). Ethnography: Principles in practice. Routledge.

[8] S. C. B. Sampaio, M. L. M. Marinho and H. P. Moura (2014). An Approach to Understanding Project Actuality in Small Software Development Organizations and Contribute to Their Success. ProjMAN - International Conference on Project MANagement, 2014, Troia.

[9] S. C. B. Sampaio, M. L. M. Marinho and H. P. Moura (2014). Systematic Review on Project Actuality. IJCSIT.

[10] M.V. Zelkowitz, D. Wallace (1997). Experimental validation in software engineering. Information and Software Technology, 39 (11), 735-743.

[11] S. Easterbrook, J. Singer, M. Storey, D. Damian (2008). Selecting empirical methods for software engineering research. Guide to advanced empirical software engineering, 285-311.

[12] R. Davison, M. G. Martinsons, N. Kock (2004). Principles of canonical action research. Information systems journal, 14(1), 65-86.

[13] SOFTEX (2012). MPS.BR General Guide. Mps.br guia geral 2012.

[14] Schensul, S. L. (1999). Essential ethnographic methods: Observations, interviews, and questionnaires (Vol. 2). Rowman Altamira.

[15] S. Cicmil, T. Williams, J. Thomas and D. Hodgson (2006). Rethinking project management: researching the actuality of projects. International Journal of Project Management, 24(8), 675-686.

[16] S. Cicmil (2006). Understanding project management practice through interpretative and critical research perspectives. Project management journal, 37(2), 27-37.

[17] L. Crawford. Developing organizational project management capability: theory and practice. Project Management Journal, 37(3):74-97, 2006. 